\title{
Some Remarks about Modelling of Annular Three-Layered Plate Structure
}

\author{
Dorota Pawlus \\ Faculty of Mechanical Engineering and Computer Science, University of Bielsko-Biała, \\ Willowa 2, 43-309 Bielsko-Biała, Poland
}

\begin{abstract}
The evaluation of the influence of the examined mesh structure on the computational results is considered in this paper. The annular plates with three-layered, cross-section structure having the soft core in the range of critical behaviour after loss of static and dynamic stability have been analysed. Several meshes of plate models, which can be applied in numerical calculations have been presented. The results obtained in finite element method have been compared with the results of plates solved using the finite difference method. The analysis has been undertaken in the wide range of the examined problems taking into account not only the global forms of plate critical deformations but also the other local ones and analysing different plate buckling forms with several transverse waves in circumferential direction, too. In the discussion the rate of the sensitivity of the presented plate models depending on their problem application has been noticed.
\end{abstract}

Keywords: mesh model, sandwich plate, static, dynamic stability, FEM, FDM.

\section{Introduction}

The different critical and overcritical behaviours of the sandwich structure of plates under lateral loads require building of the proper computational model. The geometrical and material parameters of the component layers of the structure essentially determine its behaviour, especially, when there are significant differences among them. Widely examined structure of three-layered plate with soft, foam, thick core is exactly such object, which computational model shows the significant sensitivity for the accepted parameters describing it. The way of building of such structure of plate with annular shape, which enables the solution to the static and dynamic plate problem, with the indication on its computational sensitivity has been considered in this paper. In the range of the axisymmetric dynamic stability problems of sandwich plates ( among others ) recently appeared works [1], [2] could be mentioned.

\section{Problem Formulation}

The problem undertaken in this paper consists in the evaluation of the influence of the model structure of the three-layered plate on the computational results. The annular 
plate with the soft core compressed in the facings plane by the loads acting on the inner or/and outer their perimeters is the subject of the analysis. The scheme of plate loading is presented in Fig. 1. Such loads make the loss of plate stability, characterized by the critical parameters, like: critical static or dynamic load, form of buckling and critical deflection. These quantities for the plate examples differing in the model built by means of the finite element method have been analysed in this work.

The examined, exemplary plate has the slidably clamped edges; symmetrical crosssectional structure and the following material and geometrical parameters:

- the inner radius $r_{i}=0.2 \mathrm{~m}$;

- the outer radius $r_{0}=0.5 \mathrm{~m}$;

- the facing thickness (equal for each facing ) $h^{\prime}=0.0005 \mathrm{~m}$ or $h^{\prime}=0.001 \mathrm{~m}$;

- the core thickness $\mathrm{h}_{2}=0.005 \mathrm{~m}, 0.02 \mathrm{~m}, 0.06 \mathrm{~m}$;

- the steel facing material with Young's modulus E $=2.1 \cdot 10^{5} \mathrm{MPa}$, Poisson's ratio $v=0.3$ and mass density $\mu=7.85 \cdot 10^{3} \mathrm{~kg} / \mathrm{m}^{3}$;

- two polyurethane foam core material with the value of Kirchhoff's modulus equal to $\mathrm{G}_{2}=5 \mathrm{MPa}$ and mass density $\mu_{2}=64 \mathrm{~kg} / \mathrm{m}^{3}$ [3] or with $\mathrm{G}_{2}=15.82 \mathrm{MPa}$ and $\mu_{2}=93.6$ $\mathrm{kg} / \mathrm{m}^{3}$ [4]; value of Poisson's ratio, equal to $\mathrm{v}=0.3$ and values of Young's modulus $\mathrm{E}_{2}=13 \mathrm{MPa}$ and $\mathrm{E}_{2}=41.13 \mathrm{MPa}$ calculated treating the foam material as an isotropic, respectively.

a)

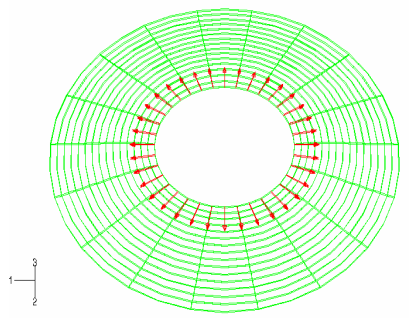

b)

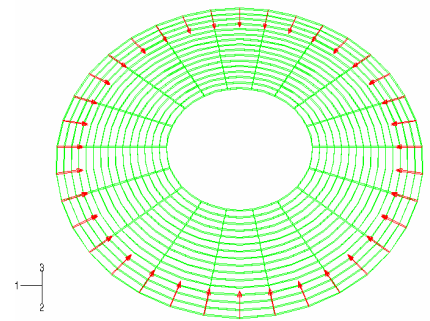

Fig. 1. The scheme of plate loaded: a) on the inner perimeter, b) on the outer perimeter

The obtained results in finite element method have been compared with the computational results of plates solved using the finite difference method. Building the models of plate structure solved in both methods: finite element (FEM) and finite difference (FDM) the distribution of the basic stress on the normal and shearing carrying by the plate layers: facings and core has been used. Such loading distribution of the layers of plate with soft core is the assumption of the classical theory of sandwich plate. In work [5] the proposal of the application of the mixed shell and solid elements in mesh structure has been presented. It has been used in the modelling of the structure of the analysed plate. The application of the shell elements with the option COMPOSITE to specify a shell cross-section for the plates with soft core does not assure the proper results in plate stability problem. The calculations of the plate models built of shell elements for elastic core characteristics corresponding to the facings material parameters have been presented in work [6]. 


\subsection{Plate Models Built in Finite Element Method}

The calculations were carried out in the ABAQUS system at the Academic Computer Center CYFRONET-CRACOW (KBN/SGL_ORIGIN_2000/PŁódzka/030/1999) [7]. The model in the form of the full annulus of plate is the basic model accepted in problem analysis. This model is composed of the 9-node 3D shell elements and 27-node 3D solid elements building the facings and core meshes, respectively. The mesh of the model is presented in Fig. $2 \mathrm{a}$.

a).

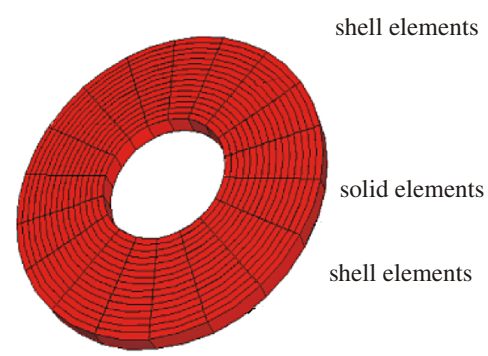

b).
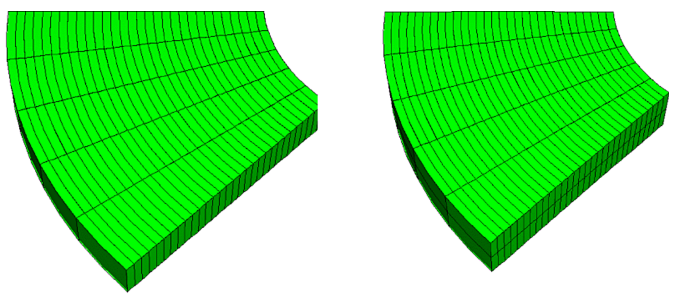

c).
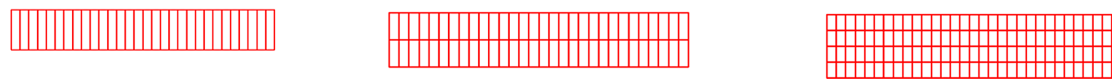

Fig. 2. The forms of plate models: a) full annulus, b) annular sector with single or double core layer, c) built of axisymmetric elements with single, double and quaternary core layer

The examinations of the selected forms of plate critical deformations have been carried out for the models in the form of an annular sector being the 1/8 or 1/6 part of the full plate perimeter. The facings mesh is built of 9-node 3D shell elements and core mesh is built of 27-node 3D solid elements, too. The solid elements could be arranged in single or double layers in core mesh. The models are presented in Fig. $2 \mathrm{~b}$.

The mesh of the model for some plate examples, which minimal value of critical load $p_{c r}$ ( important in stability problem ) corresponds to the form of regular, axiallysymmetrical buckling could be simplified to the form - where only the axisymmetric elements are used. The cross-section structure presented in Fig. 2c is composed of 3node shell and 8-node solid elements arranged in single, double and quaternary core mesh layer. The regular, axially-symmetrical form of plate buckling corresponds to the minimal value of the critical load for plates slidably clamped and compressed on inner perimeter [8].

Each of analyzed plate model uses the surface contact interaction to connect the elements of facings mesh with elements of core mesh. The option TIE has been applied. The proper, symmetry conditions on the partitioned edges have been formulated for the annular sector models. The boundary conditions with the limitation of radial relative displacements in the plate slidably clamped edges are imposed on the outer 
and inner plate edges. The introduction of the additional condition for the plate layers, by their connection with the equal deflection, increases the numbers of examined plate models.

\subsection{Solution to the Plate Stability Problem Using the Finite Difference Method}

The solution uses the classical theory of sandwich plates with the broken line hypothesis [8]. The equal deflections of plate layers have been assumed. The basic elements in the solution to the static stability problem are as follows:

- formulation of the equilibrium equations for each of plate layer,

- determination of the equations of radial and circumferential core deformation,

- formulation of the physical relations of the material of plate layers,

- on the strength of the equations of the sectional forces and moments and suitable equilibrium equations determination of the formulas of the resultant radial and circumferential forces and the resultant membrane radial, circumferential and shear forces determined by means of the introduced stress function,

- by the usage of the equilibrium equations of the projections in the 3-direction of forces loading the plate layers the formulation of the basic differential equation describing the deflections of the analyzed plate,

- determination of the additional equilibrium equations of projections in the radial and circumferential directions of forces loading the undeformed outer plate layers,

- determination of the boundary conditions and dimensionless quantities,

- assumption that the stress function is a solution to the disk state,

- application of the finite difference method for the approximation of the derivatives with respect to radius and the solution to the eigen-value problem with the calculation of the minimal value of $p^{*}$ as the critical static load $p_{c r}$ :

$$
\operatorname{det}\left((\mathbf{M A P}+\mathbf{M A D} \cdot \mathbf{M A T D}+\mathbf{M A G} \cdot \mathbf{M A T G})-\mathrm{p}^{*} \mathbf{M A C}\right)=0
$$

where: $\mathrm{p}^{*}=\frac{\mathrm{p}}{\mathrm{E}}$,

MAP, MAC, MAD, MAG, MATD, MATG - matrices of elements composed of geometric and material plate parameters and the quantity $b$ of the length of the interval in the finite differences method and the number $m$ of buckling waves.

The detailed description of the problem solution has been presented in work [9].

Presented in this work, the results of plate dynamic stability calculations have been limited to the regular, axially-symmetrical form of plate critical deformation. This form corresponds to the minimal value of critical load for analyzed plates compressed on the inner facings parameters. Then, the solution requires the formulation:

- the dynamic, equilibrium equations,

- description of the core deformation taking into account the plate imperfection,

- determination of the initial loading conditions,

- assumption of the form of plate predeflection,

- the formulation of the system of equations using the finite difference method. 
The description of the solution is presented in work [10].

The numerical calculations in finite difference method require the proper choice of the number of discrete points to fulfil the results accuracy up to $5 \%$ of the technical error. The calculation were carried out for number 14 of discrete points.

\section{Discussion of Computational Results}

The discussion of computational results of analyzed plates has been presented separating the static and dynamic stability plate problems. It was also taken notice on the examples of plates with the core thickness treated as the medium for $h_{2}$ equal to $\mathrm{h}_{2}=0.005 \mathrm{~m}, 0.02 \mathrm{~m}$ and the thick: $\mathrm{h}_{2}=0.06 \mathrm{~m}$.

\subsection{Critical Static Loads}

The observed buckling forms of analyzed plates loaded on inner edge are regular, axially-symmetrical, but the plates compressed on the outer perimeter lose their stability for the different number $m$ of the transverse waves in circumferential direction. The global, quasi-euler's forms of critical plate buckling are essentially observed. For plate with thick core are expected the primary, local forms of the loss of plate stability, when the critical deformations of plate layers (the core, particularly) do not occur for their equal deflections.

\subsubsection{Analysis of Plates with Medium Core}

The computational results of different models of plates loaded on inner edge are presented in Table 1. The critical form of deformation is the regular axially-symmetrical for all plates examples. For the each plate model it is presented in Fig. 3.

Table 1. Values of the critical static stress of plates loaded on the inner edge of facings

\begin{tabular}{|c|c|c|c|c|c|c|c|}
\hline \multirow{2}{*}{$\begin{array}{c}\mathrm{h}^{\prime}[\mathrm{m}] / \mathrm{h}_{2}[\mathrm{~m}] / \mathrm{G}_{2} \\
{[\mathrm{MPa}]}\end{array}$} & $\begin{array}{c}\text { full } \\
\text { annulus } \\
\text { plate } \\
\text { model }\end{array}$ & $\begin{array}{c}\text { model built } \\
\text { of } \\
\text { axisymmetric } \\
\text { elements }\end{array}$ & $\begin{array}{c}\text { model built } \\
\text { of } \\
\text { axisymmetric } \\
\text { elements }\end{array}$ & $\begin{array}{c}\text { annular } \\
\text { sector } \\
(1 / 8 \\
\text { part })\end{array}$ & $\begin{array}{c}\text { 1) } \\
\text { annular } \\
\text { sector } \\
(1 / 8 \\
\text { part })\end{array}$ & $\begin{array}{c}\mathrm{p}_{\text {cr }}[\mathrm{MPa}] \\
\text { annular } \\
\text { sector } \\
(1 / 8 \\
\text { part })\end{array}$ & FDM \\
\hline $0.0005 / 0.005 / 5.0$ & 57.84 & 57.48 & 57.52 & 57.73 & 57.82 & 57.78 & 64.12 \\
\hline $0.001 / 0.005 / 5.0$ & 64.08 & 64.00 & 64.00 & 62.94 & 63.15 & 63.14 & 75.61 \\
\hline $0.0005 / 0.02 / 5.0$ & 170.50 & 168.32 & 172.27 & 168.04 & 173.94 & 169.43 & 165.51 \\
\hline $0.001 / 0.02 / 5.0$ & 143.77 & 143.20 & 144.16 & 143.22 & 144.17 & 143.17 & 150.29 \\
\hline $0.0005 / 0.005 / 15.82$ & 137.93 & 136.49 & 136.63 & 137.41 & 137.66 & 137.46 & 149.91 \\
\hline $0.001 / 0.005 / 15.82$ & 120.30 & 119.92 & 119.94 & 119.21 & 119.43 & 119.38 & 149.34 \\
\hline $0.0005 / 0.02 / 15.82$ & 449.24 & 434.56 & 457.95 & 435.62 & 462.66 & 438.89 & 437.54 \\
\hline $0.001 / 0.02 / 15.82$ & 326.41 & 324.01 & 328.30 & 323.93 & 330.41 & 325.67 & 338.94 \\
\hline
\end{tabular}

${ }^{1)}$ Plate layers connected with the condition of the equal deflection.

2) Facings connected with the condition of the equal deflection.

The consistence of results of all FEM plate models is observed. The good compatibility of values of critical loads of plates calculated in finite difference and finite element methods is particularly observed for plates with the core thickness, equal to $\mathrm{h}_{2}=0.02 \mathrm{~m}$. The values of critical loads of plate models with the condition of the equal 
a)

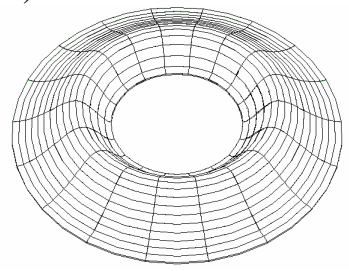

b)

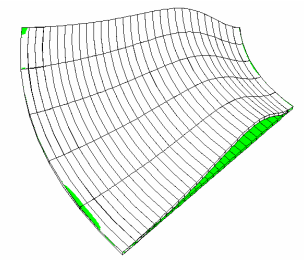

c)

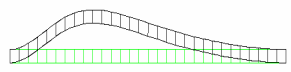

Fig. 3. Regular axially-symmetrical form of plate buckling for: a) full annulus plate model, b) annular plate sector, c) model built of axisymmetric elements

layers deflection are generally slightly higher than values obtained for plates without this condition. The increase in these values above the values calculated for FDM plate model appears for plates with thin facings $h^{\prime}=0.0005 \mathrm{~m}$ and thicker core $\left(\mathrm{h}_{2}=0.02 \mathrm{~m}\right)$.

The results of the plates compressed on outer perimeter are presented in Table 2. Table 2 contains the minimal values of critical loads $p_{c r}$ and number of buckling waves $m$. Some forms of plates buckling are presented in Fig. 4.

Table 2. Values of the critical static stress of plates loaded on the outer edge of facings

\begin{tabular}{|c|c|c|c|}
\hline \multirow{2}{*}{$\mathrm{h}^{\prime}[\mathrm{m}] / \mathrm{h}_{2}[\mathrm{~m}] / \mathrm{G}_{2}[\mathrm{MPa}]$} & \multicolumn{2}{|c|}{$\mathrm{p}_{\text {cr }}[\mathrm{MPa}]$} & \multirow{2}{*}{ FDM } \\
\cline { 2 - 4 } & full annulus plate model & $\begin{array}{c}{ }^{1)} \text { full annulus plate } \\
\text { model }\end{array}$ & $\begin{array}{c}22.37 \\
\mathrm{~m}=8\end{array}$ \\
\hline \multirow{2}{*}{$0.0005 / 0.005 / 5.0$} & 19.16 & $\begin{array}{c}19.18 \\
\mathrm{~m}=7\end{array}$ & $\begin{array}{c}20.52 \\
\mathrm{~m}=5\end{array}$ \\
\hline \multirow{2}{*}{$0.001 / 0.005 / 5.0$} & 16.48 & 16.49 & 69.49 \\
& $\mathrm{~m}=5$ & $\mathrm{~m}=5$ & $\mathrm{~m}=12$ \\
\hline \multirow{2}{*}{$0.0005 / 0.02 / 5.0$} & 66.56 & $\mathrm{~m}=9$ & 46.95 \\
& $\mathrm{~m}=10$ & 43.97 & $\mathrm{~m}=7$ \\
\hline \multirow{2}{*}{$0.001 / 0.02 / 5.0$} & 43.71 & $\mathrm{~m}=7$ & 61.51 \\
& $\mathrm{~m}=7$ & 52.10 & $\mathrm{~m}=9$ \\
\hline \multirow{2}{*}{$0.0005 / 0.005 / 15.82$} & 52.03 & $\mathrm{~m}=8$ & 46.53 \\
& $\mathrm{~m}=9$ & $\mathrm{~m}=6.06$ & $\mathrm{~m}=6$ \\
\hline \multirow{2}{*}{$0.001 / 0.005 / 15.82$} & 35.04 & 198.65 & 200.62 \\
& $\mathrm{~m}=6$ & $\mathrm{~m}=12$ & $\mathrm{~m}=18$ \\
\hline \multirow{2}{*}{$0.0005 / 0.02 / 15.82$} & 193.15 & 116.31 & 125.11 \\
& $\mathrm{~m}=12$ & $\mathrm{~m}=8$ & $\mathrm{~m}=9$ \\
\hline \multirow{2}{*}{$0.001 / 0.02 / 15.82$} & 115.10 & $\mathrm{~m}=9$ & \\
\hline
\end{tabular}

1) Plate layers connected with the condition of the equal deflection.

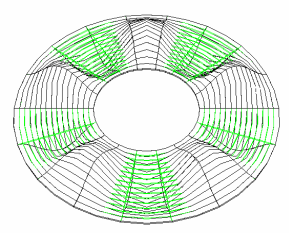

$\mathrm{m}=5$

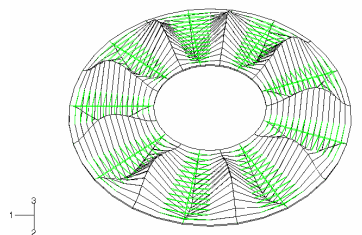

$m=9$

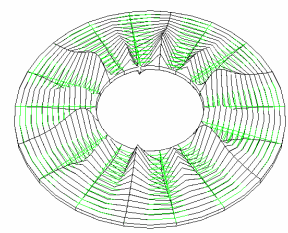

$\mathrm{m}=12$

Fig. 4. The forms of critical plate deformations 
Results show the slightly increase in values of critical loads of plates with the condition of the equal layers deflection. Then, the change of plate buckling in the form of the decrease in the number $m$ waves could occur.

Additionally, in Table 3 the results of the select plate examples obtained for the annular sector of plate model are presented. These values of critical loads are suitably higher than results obtained for full annulus plate model.

Table 3. Critical static loads for plate examples compressed on outer edges with the results of the model of plate annular sector

\begin{tabular}{|c|c|c|c|c|c|c|}
\hline \multirow[b]{2}{*}{$\begin{array}{c}\mathrm{h}^{\prime}[\mathrm{m}] / \mathrm{h}_{2}[\mathrm{~m}] / \mathrm{G}_{2} \\
{[\mathrm{MPa}]}\end{array}$} & \multicolumn{6}{|c|}{$\mathrm{p}_{\mathrm{cr}}[\mathrm{MPa}]$} \\
\hline & $\begin{array}{l}\text { full annulus } \\
\text { plate model }\end{array}$ & $\begin{array}{c}{ }^{1)} \text { full } \\
\text { annulus } \\
\text { plate model }\end{array}$ & $\begin{array}{c}\text { annular } \\
\text { sector } \\
\text { (1/6 part) }\end{array}$ & $\begin{array}{c}\text { annular } \\
\text { sector } \\
\text { (1/8 part) }\end{array}$ & $\begin{array}{l}\text { 1) annular } \\
\text { sector } \\
\text { (1/8 part) }\end{array}$ & FDM \\
\hline $0.0005 / 0.005 / 15.82$ & $\begin{array}{c}52.03 \\
\mathrm{~m}=9\end{array}$ & $\begin{array}{c}52.10 \\
\mathrm{~m}=8\end{array}$ & $\begin{array}{c}52.75 \\
\mathrm{~m}=9\end{array}$ & $\begin{array}{c}52.63 \\
\mathrm{~m}=8\end{array}$ & $\begin{array}{c}55.26 \\
\mathrm{~m}=8\end{array}$ & $\begin{array}{c}61.51 \\
\mathrm{~m}=9\end{array}$ \\
\hline $0.001 / 0.005 / 15.82$ & $\begin{array}{c}35.04 \\
m=6\end{array}$ & $\begin{array}{c}35.06 \\
\mathrm{~m}=6\end{array}$ & $\begin{array}{c}36.74 \\
m=6\end{array}$ & - & - & $\begin{array}{c}46.53 \\
m=6\end{array}$ \\
\hline $0.001 / 0.02 / 15.82$ & $\begin{array}{c}115.10 \\
m=9\end{array}$ & $\begin{array}{c}116.31 \\
m=8\end{array}$ & $\begin{array}{c}123.23 \\
\mathrm{~m}=9\end{array}$ & $\begin{array}{c}124.43 \\
m=8\end{array}$ & $\begin{array}{c}116.65 \\
m=8\end{array}$ & $\begin{array}{c}125.11 \\
\mathrm{~m}=9\end{array}$ \\
\hline
\end{tabular}

${ }^{1)}$ Plate layers connected with the condition of the equal deflection.

\subsubsection{Analysis of Plates with Thick Core}

The results of various models of plates compressed on inner perimeter are presented in Table 4 . The results marked by * concern the plate models, which critical deformation has not the regular, axially-symmetrical form. For all examined models the decrease in values of critical loads and the change in the form of critical deformation is observed for the plates with thin facings $h^{\prime}=0.0005 \mathrm{~m}$ and thick core $\mathrm{h}_{2}=0.06 \mathrm{~m}$ and particularly for the core Kirchhoff's moduls equal to $\mathrm{G}_{2}=15.82 \mathrm{MPa}$. The examples forms of critical deformations are presented in Fig. 5.

Table 4. Values of the critical loads of plates with thick core loaded on the inner edge

\begin{tabular}{|c|c|c|c|c|c|}
\hline \multirow[b]{2}{*}{$\begin{array}{c}\mathrm{h}^{\prime}[\mathrm{m}] / \mathrm{h}_{2}[\mathrm{~m}] / \mathrm{G}_{2} \\
{[\mathrm{MPa}]}\end{array}$} & \multicolumn{5}{|c|}{$\mathrm{p}_{\mathrm{cr}}[\mathrm{MPa}]$} \\
\hline & $\begin{array}{l}\text { full annulus } \\
\text { plate model }\end{array}$ & $\begin{array}{l}\text { model built of } \\
\text { axisymmetric } \\
\text { elements }\end{array}$ & $\begin{array}{l}{ }^{1)} \text { model built } \\
\text { of } \\
\text { axisymmetric } \\
\text { elements }\end{array}$ & $\begin{array}{l}{ }^{3)} \text { model built } \\
\text { of } \\
\text { axisymmetric } \\
\text { elements }\end{array}$ & $\begin{array}{l}{ }^{4)} \text { model built of } \\
\text { axisymmetric } \\
\text { elements }\end{array}$ \\
\hline $0.0005 / 0.06 / 5.0$ & 347.54 & 345.48 & 440.20 & 315.53 & 309.47 \\
\hline $0.001 / 0.06 / 5.0$ & 293.90 & 292.68 & 317.34 & 288.45 & 287.84 \\
\hline $0.0005 / 0.06 / 15.82$ & $791.37 *$ & $774.10 *$ & 1238.81 & $684.19 *$ & $649.49 *$ \\
\hline $0.001 / 0.06 / 15.82$ & $689.10 *$ & 686.66 & 796.31 & 659.77 & 655.17 \\
\hline $\begin{array}{c}\mathrm{h}^{\prime}[\mathrm{m}] / \mathrm{h}_{2}[\mathrm{~m}] / \mathrm{G}_{2} \\
{[\mathrm{MPa}]}\end{array}$ & $\begin{array}{l}\text { annular sector } \\
\text { (1/8 part) }\end{array}$ & $\begin{array}{l}\text { 1) annular } \\
\text { sector } \\
\text { (1/8 part) }\end{array}$ & $\begin{array}{l}\text { 2) annular } \\
\text { sector } \\
\text { (1/8 part) }\end{array}$ & $\begin{array}{l}{ }^{3)} \text { annular } \\
\text { sector } \\
\text { (1/8 part) }\end{array}$ & FDM \\
\hline $0.0005 / 0.06 / 5.0$ & 329.58 & 445.26 & $324.10 *$ & $251.81 *$ & 406.98 \\
\hline $0.001 / 0.06 / 5.0$ & 291.53 & 319.62 & 293.01 & 279.29 & 312.53 \\
\hline $0.0005 / 0.06 / 15.82$ & $718.51 *$ & 1252.27 & $670.41 *$ & $511.49 *$ & 1191.70 \\
\hline $0.001 / 0.06 / 15.82$ & 676.11 & 804.84 & 677.64 & $586.19 *$ & 749.53 \\
\hline
\end{tabular}

${ }^{1)}$ Plate layers connected with the condition of the equal deflection.

2) Facings connected with the condition of the equal deflection.

3) The core mesh built of two layers of solid elements.

4) The core mesh built of four layers of solid elements. 
The results obtained for plates with connected layers by the condition of the equal deflection are the obvious exception. Then, the values of loads and the global buckling forms correspond to the results obtained for plates models calculated in FDM. It could be suspected that these values are too high. The values of critical loads of plates models built of two or four layers of the core elements are lower than values obtained for the models with single core layer. Particularly, the essential decrease in values of critical loads is observed for the plate model in the form of the annular sector with the double core layer.

a)

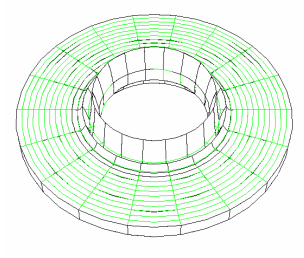

$\mathrm{p}_{\mathrm{cr}}=791.37 \mathrm{MPa}$ b)

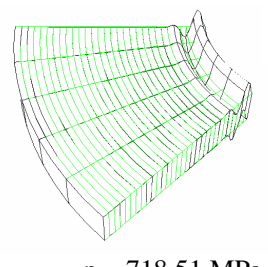

c)

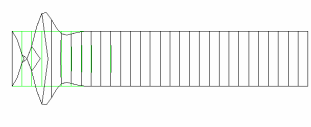

$\mathrm{p}_{\mathrm{cr}}=774.10 \mathrm{MPa}$ d)

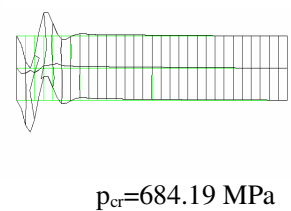

Fig. 5. The forms of buckling of plate models: a) full annulus, b) annular sector, c) model built of axisymmetric elements, d) model built of two layers of core axisymmetric elements

The sensitivity of plate models with thin facings and thick core is observed for plate compressed on the outer perimeter, too. Example results are presented in Table 5.

Table 5. Values of the critical loads of plates with thick core loaded on the outer edge

\begin{tabular}{|c|c|c|c|c|}
\hline \multirow[b]{2}{*}{$\mathrm{h}^{\prime}[\mathrm{m}] / \mathrm{h}_{2}[\mathrm{~m}] / \mathrm{G}_{2}[\mathrm{MPa}]$} & \multicolumn{4}{|c|}{$\mathrm{p}_{\mathrm{cr}}[\mathrm{MPa}]$} \\
\hline & $\begin{array}{l}\text { full annulus plate } \\
\text { model }\end{array}$ & $\begin{array}{l}{ }^{1)} \text { full annulus } \\
\text { plate model }\end{array}$ & $\begin{array}{l}\text { 1) annular sector } \\
\text { (1/8 part) }\end{array}$ & FDM \\
\hline $0.0005 / 0.06 / 5.0$ & $149.37 *$ & $\begin{array}{c}189.45 \\
m=12\end{array}$ & $\begin{array}{c}187.15 \\
m=20\end{array}$ & $\begin{array}{c}185.68 \\
\mathrm{~m}=17\end{array}$ \\
\hline $0.001 / 0.06 / 5.0$ & $\begin{array}{c}102.86 \\
m=9\end{array}$ & $\begin{array}{c}111.60 \\
m=8\end{array}$ & $\begin{array}{c}124.92 \\
m=8\end{array}$ & $\begin{array}{c}113.39 \\
\mathrm{~m}=9\end{array}$ \\
\hline $0.0005 / 0.06 / 15.82$ & $402.44 *$ & $\begin{array}{c}571.69 \\
\mathrm{~m}=14\end{array}$ & $\begin{array}{c}519.03 \\
m=24\end{array}$ & $\begin{array}{c}542.70 \\
\mathrm{~m}=27\end{array}$ \\
\hline $0.001 / 0.06 / 15.82$ & $\begin{array}{c}274.23 \\
\mathrm{~m}=12\end{array}$ & $\begin{array}{c}318.34 \\
m=10\end{array}$ & $\begin{array}{c}343.26 \\
m=12\end{array}$ & $\begin{array}{c}320.63 \\
\mathrm{~m}=12\end{array}$ \\
\hline
\end{tabular}

${ }^{1)}$ Plate layers connected with the condition of the equal deflection.

Also for plates loaded on the outer edge the values of critical loads of models with connected layers seem to be to high. Results obtained for the annular sector of plate with the connected layers are both in values of critical loads and the forms of buckling closer to the results obtained in finite difference method.

\subsection{Critical Dynamic Loads}

The calculations of the critical dynamic loads have been carried out for the plates compressed on inner edges of the facings with the linear, rapidly increasing stress expressed by the formula: 
where:

$$
\mathrm{p}=\mathrm{st}
$$

$\mathrm{p}$ - compressive stress, $\mathrm{s}$ - rate of plate loading growth, $\mathrm{t}$ - time.

The rate of plate loading growth $s$ is equal for each of numerical analysed plate. The value of the rate $s$ is the result of the following equation: $s=K 7 \cdot \mathrm{p}_{\mathrm{cr}}$. The value of parameter $K 7$ is accepted as $\mathrm{K} 7=20$. Solving the eigenproblem the value of critical stress $p_{c r}$ is equal: $\mathrm{p}_{\mathrm{cr}}=217.3 \mathrm{MPa}$ calculated for the plate with the facing thickness $\mathrm{h}^{\prime}=0.001 \mathrm{~m}$, core thickness $\mathrm{h}_{2}=0.01 \mathrm{~m}$ and the value of core Kirchhoff's modulus equal: $\mathrm{G}_{2}=15.82 \mathrm{MPa}$.

The calculations are carried out for the regular, axially-symmetrical form of plate buckling. This form has the plate predeflection, too. As the criterion of loss of plate stability, the criterion presented in work [11] was adopted. According to this criterion the loss of plate stability occurs at the moment of time when the speed of the point of maximum deflection reaches the first maximum value.

The results of some plate examples obtained using the finite element method in the form of time histories of plate maximum deflection and the velocity of deflection are

a)

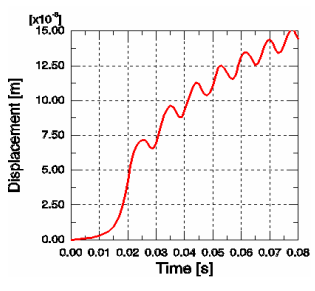

b)

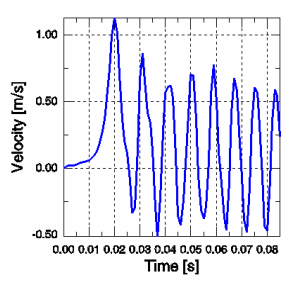

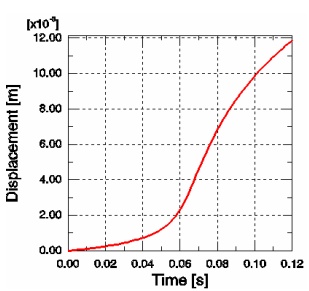

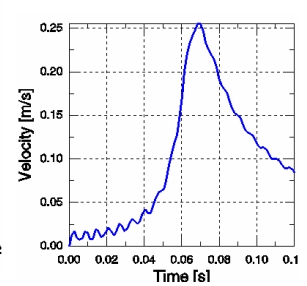

Fig. 6. Time histories of deflection and velocity of deflection for plates with parameters: a) $\left.\mathrm{h}^{\prime}=0.001 \mathrm{~m}, \mathrm{~h}_{2}=0.005 \mathrm{~m}, \mathrm{G}_{2}=5 \mathrm{MPa}, \mathrm{b}\right) \mathrm{h}$ ' $=0.001 \mathrm{~m}, \mathrm{~h}_{2}=0.06 \mathrm{~m}, \mathrm{G}_{2}=5 \mathrm{MPa}$

Table 6. Values of the critical, dynamic loads $p_{c r d y n}$ and critical deflections $w_{c r}$ of plates loaded on the inner edge

\begin{tabular}{|c|c|c|c|c|c|}
\hline \multirow{2}{*}{$\mathrm{h}^{\prime}[\mathrm{m}] / \mathrm{h}_{2}[\mathrm{~m}] / \mathrm{G}_{2}[\mathrm{MPa}]$} & \multicolumn{5}{|c|}{$\mathrm{p}_{\text {crdyn }}[\mathrm{MPa}]$} \\
& $\mathrm{w}_{\text {cr }} 10^{-3}[\mathrm{~m}]$ \\
& $\begin{array}{c}\text { full annulus } \\
\text { plate model }\end{array}$ & $\begin{array}{c}\text { model built of } \\
\text { axisymmetric } \\
\text { elements }\end{array}$ & $\begin{array}{c}\text { annular sector } \\
(1 / 8 \text { part })\end{array}$ & $\begin{array}{c}\text { 3) annular } \\
\text { sector } \\
(1 / 8 \text { part })\end{array}$ & FDM \\
\hline \multirow{2}{*}{$0.001 / 0.005 / 5.0$} & 91.27 & 86.93 & 86.93 & 86.92 & 98.88 \\
& 4.25 & 3.28 & 4.38 & 4.38 & 3.92 \\
\hline \multirow{2}{*}{$0.001 / 0.02 / 5.0$} & 152.11 & 147.78 & 147.78 & 147.76 & 159.30 \\
& 3.13 & 2.94 & 3.56 & 3.57 & 3.77 \\
\hline \multirow{2}{*}{$0.001 / 0.06 / 5.0$} & 304.22 & 304.22 & 299.87 & 291.18 & 321.65 \\
& 4.16 & 4.35 & 4.80 & 4.42 & 5.21 \\
\hline \multirow{2}{*}{$0.001 / 0.005 / 15.82$} & 136.90 & 139.10 & 134.74 & 134.73 & 166.69 \\
& 3.08 & 3.67 & 4.31 & 4.31 & 3.87 \\
\hline \multirow{2}{*}{$0.001 / 0.02 / 15.82$} & 330.30 & 326.0 & 326.0 & 325.95 & 346.64 \\
& 2.99 & 3.08 & 3.88 & 3.9 & 4.25 \\
\hline
\end{tabular}

${ }^{3)}$ The core mesh built of two layers of solid elements. 
presented in Fig. 6. Table 6 shows the values of critical, dynamic loads and critical deflections for the plate models built in finite element and finite difference methods. The results obtained in FEM indicate a mutually good consistency. For plate with thicker core $\mathrm{h}_{2}=0.02 \mathrm{~m}$ and $0.06 \mathrm{~m}$ these results correspond to the results obtained in finite difference method, too. The major fluctuations are observed for the plate critical deflections. The calculations show that in dynamic problem in the range of the global buckling observations the influence of the plate structure built in finite element method on the final results is not so essential, like is static analysis.

\section{Conclusions}

The results obtained for presented different models, which are possible to application in computational plate examinations, indicate on some sensitivity of their structures. The observed differences of values of critical loads, particularly of plates with thick core are in the range of the dozens MPa. Therefore, these differences are significant. Particularly, this problem concerns the static stability issue, when other than global critical forms could occur. The study of the mesh structure of these plates models seems to be especially important. The lowest values of critical loads are for plate models with the mesh core composed of the several layers of solid elements. The computational results of these models could be the essential complement to the plate examinations carried out for their basic model in the form of full annulus.

Comparing the computational results of plates calculated in two methods: finite element and finite difference essentially, it can be determined the compatibility of the results of plate models with medium core. The consistency of results of plates with thick core is observed for these cases of plate models, which critical deformation has the global, quasi-euler's form. Then, the values of critical, static loads could be really to high.

\section{References}

1. Wang, H.J., Chen, L.W.: Axisymmetric dynamic stability of sandwich circular plates. Composite Structures 59, 99-107 (2003)

2. Chen, Y.R., Chen, L.W., Wang, C.C.: Axisymmetric dynamic instability of rotating polar orthotropic sandwich annular plates with a constrained damping layer. Composite Structures 73(2), 290-302 (2006)

3. Majewski, S., Maćkowski, R.: Creep of Foamed Plastics Used as the Core of Sandwich Plate. Engineering and Building Industry (Inżynieria i Budownictwo) 3, 127-131 (1975) (in Polish)

4. Romanów, F.: Strength of Sandwich Constructions, WSI, Zielona Góra, Poland (1995) (in Polish)

5. Kluesener, M.F., Drake, M.L.: Mathematical Modelling. Damped Structure Design Using Finite Element Analysis, Shock and Vibration Bulletin 52, 1-12 (1982)

6. Pawlus, D.: Homogeneous and sandwich elastic and viscoelastic annular plates under lateral variable loads. In: Proceedings of the Third International Conference on Thin-Walled Structures, pp. 515-522. Elsevier Science, Amsterdam (2001) 
7. Hibbitt, Karlsson and Sorensen, Inc.: ABAQUS/Standard. User's Manual, version 6.1 (2000)

8. Volmir, C.: Stability of Deformed System. Science, Moskwa (1967) (in Russian)

9. Pawlus, D.: Solution to the Static Stability Problem of Three-Layered Annular Plates With a Soft Core. Journal of Theoretical and Applied Mechanics 44(2), 299-322 (2006)

10. Pawlus, D.: Dynamic Stability Problem of Three-Layered Annular Plate under Lateral Time-Dependent Load. Journal of Theoretical and Applied Mechanics 43(2), 385-403 (2005)

11. Volmir, C.: Nonlinear Dynamic of Plates and Shells. Science, Moskwa (1972) (in Russian) 